\title{
DAMPED VIBRATIONS OF TELESCOPIC CRANE BOOM
}

\author{
M. Bold*, S. Garus ${ }^{* *}$, W. Sochacki ${ }^{* * *}$
}

\begin{abstract}
In this paper, the influence of different kinds of damping on vibrations of truck-mounted crane boom is presented. Vibration energy dissipation during changing the boom radius is caused by simultaneous internal damping of viscoelastic material of beams that model the system and constructional damping which is derived from the rotary viscous damper in the support and from the translational dampers in slides of telescopic boom. In this work, damped vibration frequencies and the degree of vibration amplitude decay for selected values of the damping coefficients and variable geometry of the system were calculated.
\end{abstract}

Keywords: truck crane, damped vibration, eigenvalues, telescopic boom, rotational damper

\section{Introduction}

Numerous studies have been published on vibration of the system for changing the boom radius in truckmounted cranes, with particular focus on vibration of only the telescopic crane. Studies by Sochacki (2007) and Geisler et al. (2011) presented examinations of vibration of truck-mounted cranes as continuous-discrete models. The investigations of vibration in the system for changing the telescopic boom radius (as a separated system in the crane) have been presented in the studies, e.g. (Chin et al., 2001; Cekus et al., 2011; Sochacki et al.,1999). These studies have examined free vibration and/or parametric vibration of this system with linear or non-linear characteristics. The above studies have not analysed damping in the system. The analysis of the effect of structural damping called "constructional damping" modelled with rotational dampers has been demonstrated in preliminary studies Sochacki and Bold (2014, 2015a). The effect of damping of supports and internal damping of material on vibration in the system for changing the boom radius has been discussed in the paper Sochacki et al. (2015b).

This study presents damped vibration of a telescopic boom of crane DUT0203, with vibration energy dissipation as a result of simultaneous internal damping of viscoelastic material of beams that model the system and from addiction of rotational viscous damper to the model at the point of attachment of boom to the bodywork frame and translational dampers that model motion resistance in slides of boom. The study evaluated damped vibration frequencies and the degree of decay of vibration amplitudes.

\section{Physical and mathematical models of the system}

The physical model of the system for changing the boom radius was presented in Fig. 1. The angle of inclination for the boom is controlled by a cylinder for changing the boom radius modelled with a spring (stiffness coefficient $-k_{S}$ ). The model takes into consideration the force caused by the cargo hung on a rope acting on the crane boom head $P=50[\mathrm{kN}]$, actual geometry of the system determined by angles $\alpha$ and $\delta$ and equivalent system rigidity.

Damping coefficients of rotational viscous dampers were denoted as $C_{R 31}$ for constructional damping in the crane support and $R_{1}-R_{4}$ for damping in slide blocks. The model of considered system also takes into

\footnotetext{
* Marta Bold, PhD.: Institute of Mechanics and Machine Design Fundamentals, Częstochowa; PL, bold@imipkm.pcz.pl

** Sebastian Garus, PhD.: Institute of Mechanics and Machine Design Fundamentals, Częstochowa; PL, garus@imipkm.pcz.pl

**** Assoc. Prof. Wojciech Sochacki, PhD.: Institute of Mechanics and Machine Design Fundamentals, Częstochowa; PL, sochacki@imipkm.pcz.pl
} 


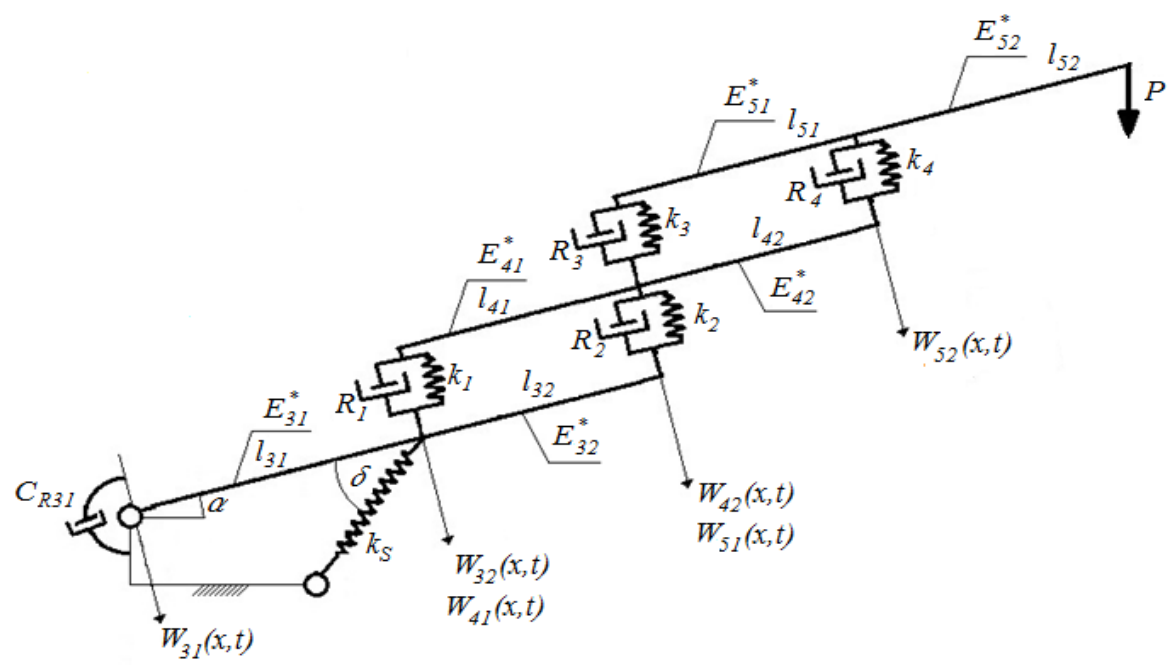

Fig. 1: Physical scheme of the studied system.

account the viscoelasticity of the material characterized by Young's modulus $E_{m n}$ and viscosity coefficients $E_{m n}^{*}$.

Formulation of the boundary problem was carried out using the Hamiltion's principle:

$$
d \int_{t_{1}}^{t_{2}}(T-V) d t+\int_{t_{1}}^{t_{2}} d W_{N} d t=0
$$

Equations of motion for individual beams in the model were denoted as:

$$
\begin{gathered}
E_{m n} J_{m n n} \frac{\partial^{4} W_{m n}\left(x_{m n}, t\right)}{\partial^{4} x_{m n}}+E_{m n}^{*} J_{m+n} \frac{\partial^{5} W_{m n}\left(x_{m n}, t\right)}{\partial^{4} x_{m m} \partial t}+P_{m n} \frac{\partial^{2} W_{m n}\left(x_{m n}, t\right)}{\partial^{2} x_{m n}}+ \\
+r_{m n} A_{m n} \frac{\partial^{2} W_{m n}\left(x_{m n}, t\right)}{\partial^{2} t}=0
\end{gathered}
$$

where: $W_{m n}(x, t)$ - lateral displacement of beams, $A_{m n}$ - beam section areas, $J_{m n}$ - the moment of inertia for beam sections, $\rho_{m n}$ - the density of the beam material, $P_{m n}$ - longitudinal forces in beams modelling the boom and the hydraulic cylinder of radius change, $x$ - space coordinate, $t$ - time, $m=3-5 ; n=1,2 ; i=1^{-1 / 2}$. Solutions of equations (2) are in the form:

$$
W_{m n t}\left(x_{m H}, t\right)=w_{m H}\left(x_{m H}\right) e^{i W^{*} t}
$$

Substitution of (3) into (2) leads to:

$$
w_{m n}^{I I}\left(x_{m n}\right)+b_{m n}^{2} w_{m n}^{I I}\left(x_{m n}\right)-g_{m n} w_{m+n}\left(x_{m n}\right)=0
$$

where:

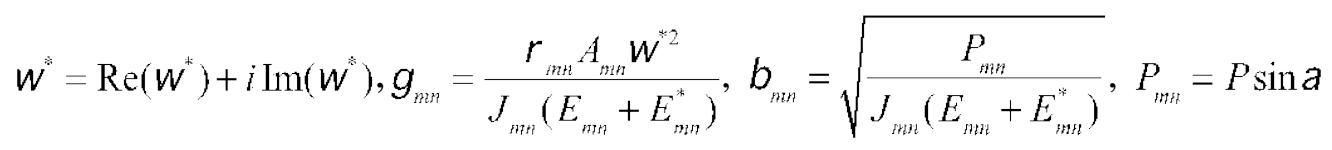

Substitution of solutions of the equations (4) to the known and the calculated boundary conditions of the system (Fig. 1) yields a homogeneous system of equations. Solving this system of equation helps determine eigenvalues in the system studied (the damped frequency $-\operatorname{Re}\left(\omega^{*}\right)$ and the degree of amplitude decay $\left.-\operatorname{Im}\left(\omega^{*}\right)\right)$

\section{Results of numerical calculations}

The results presented in Figs. 2-4 take into consideration the effect of constructional damping in supports and slides and internal damping on vibration frequency and degree of decay of vibration amplitudes in a 
telescopic boom crane, where $L_{C}$ - total crane boom length [m], $\alpha$ - crane boom inclination angle $\left[^{\circ}\right], \mu_{1^{-}}$ $\mu_{4}$ - damping coefficient in slides, $\mu_{31}$ - damping coefficient of support, $\eta$ - internal damping coefficient, $k_{1}-k_{4}-$ spring stiffness in slides:

$$
\begin{aligned}
& m_{31}=\frac{C_{R 31}}{L_{C} \sqrt{r_{31} A_{31} E_{31} J_{31}}}, h=\frac{E_{m n t}^{*}}{k E_{m n}}, k_{1}=k_{2}=\frac{K_{1} J_{31}\left(l_{31}+l_{32}\right)^{3}}{E_{31} J_{31}}, k_{3}=k_{4}=\frac{K_{3} J_{41}\left(l_{41}+l_{42}\right)^{3}}{E_{42} J_{42}} \text {, } \\
& m_{1}=m_{\underline{1}}=\frac{R_{1}}{r_{31} A_{31}\left(l_{31}+l_{32}\right) W_{01}}, m_{3}=m=\frac{R_{3}}{r_{42} A_{42}\left(l_{41}+l_{42}\right) w_{02}} \text {, } \\
& k^{2}=L_{C} \frac{\sum_{m=3}^{5} \sum_{m=1}^{2} r_{m t n} A_{m t n}}{\sum_{m=3}^{5} \sum_{m=1}^{2} E_{m m} J_{m m n}}, W_{i 11}^{2}=\frac{E_{31} J_{31}}{r_{31} A_{31}\left(l_{31}+l_{32}\right)^{4}}, W_{012}^{2}=\frac{E_{42} J_{42}}{r_{42} A_{42}\left(l_{41}+l_{42}\right)^{4}} \text {. }
\end{aligned}
$$
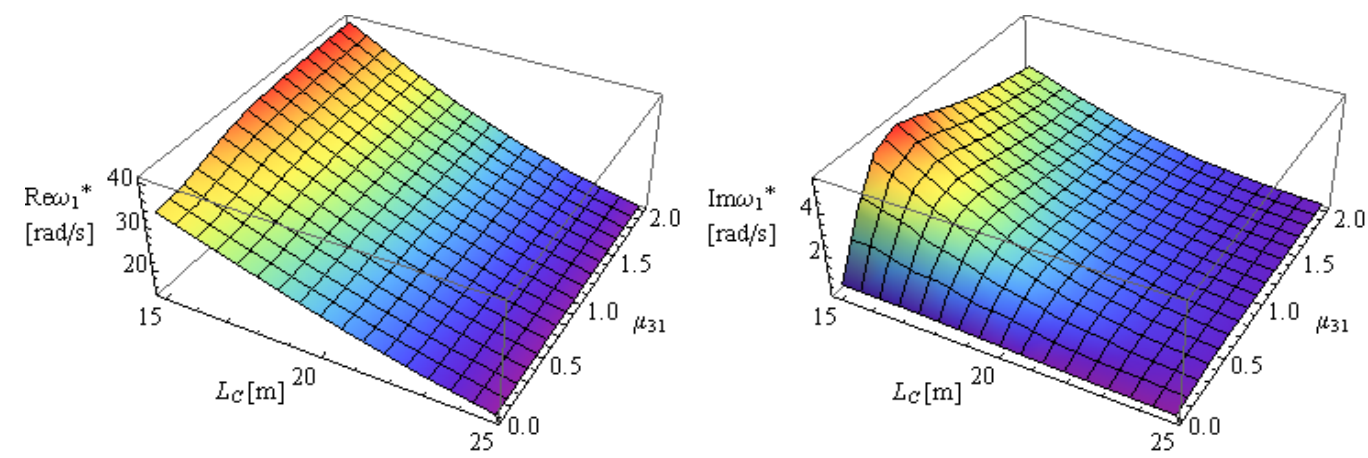

Fig. 2: The dependency of real and imaginary part of the first eigenvalue of the system $L_{C}$ and $\mu_{31}$ for $\alpha=55, k=10, \mu_{1}=\mu_{3}=\mu_{S}=1$, and $\eta=0.002$.
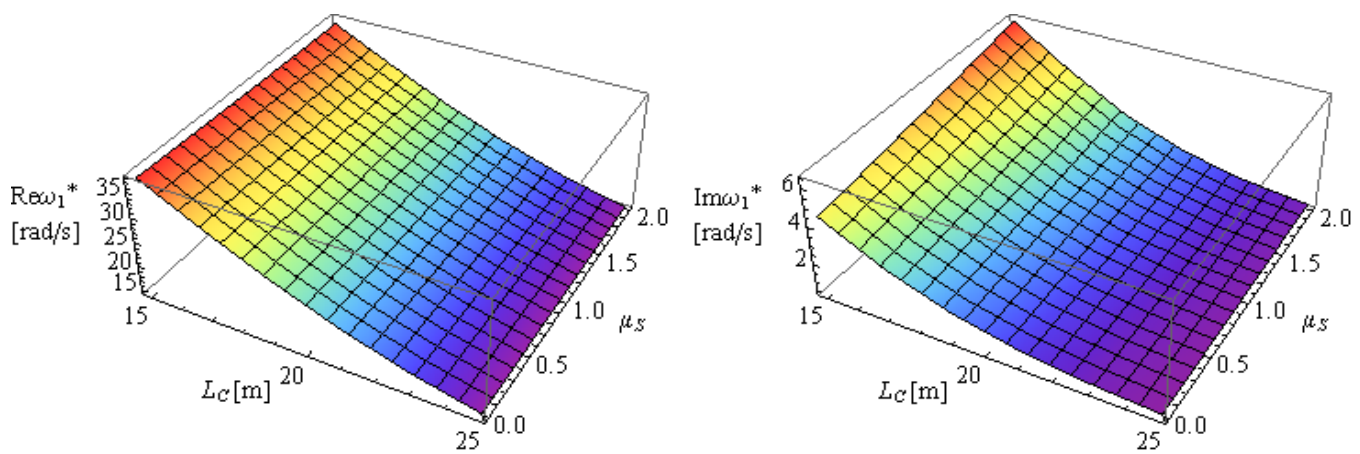

Fig. 3: The dependency of real and imaginary part of the first eigenvalue of the system $L_{C}$ and $\mu_{S}$ for $\alpha=55, k=10, \mu_{31}=0.6$, and $\eta=0.002$.
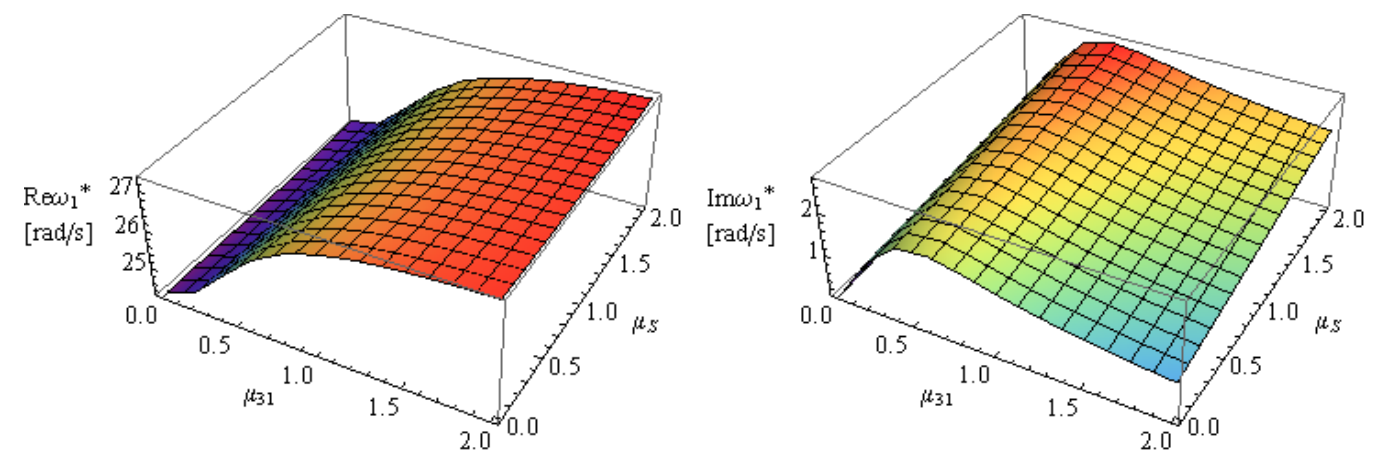

Fig. 4: The dependency of real and imaginary part of the first eigenvalue of the system $\mu_{31}$ and $\mu_{S}$ for $\alpha=55, L_{C}=19, k=10$ and $\eta=0.002$. 


\section{Conclusions}

The study presents a beam model of a telescopic boom construed based on the actual truck-mounted crane DUT0203. The effect of constructional damping in crane boom slides and its support to the rotational bodywork frame and change length $L_{C}$ on system eigenvalues were examined. The results obtained in the study lead to the conclusion that changes in the value of constructional damping of support $\mu_{31}$ for selected value of coefficient of damping in slides $\mu_{S}$ causes greater changes in damped values of vibration frequencies $\left(\operatorname{Re}\left(\omega^{*}\right)\right)$ of the system compared to changes in coefficient $\mu_{S}$ for selected value $\mu_{31}$. Increase in $\mu_{31}$ causes an increase in the degree of amplitude decay $\operatorname{Im}\left(\omega^{*}\right)$ to maximum values, followed by $\operatorname{Im}\left(\omega^{*}\right) \rightarrow 0$ where $\mu_{11} \rightarrow \infty$ (Fig. 2, 3). These substantial changes in both $\operatorname{Re}\left(\omega^{*}\right)$ and $\operatorname{Im}\left(\omega^{*}\right)$ are caused by considerable intervention in the end conditions of system (in extreme cases, the support are changed from joint mounting into rigid mounting). In the case of increasing damping in crane boom slides, coefficient $\operatorname{Im}\left(\omega^{*}\right)$ rises over the whole range studied (Figs. 4). The study allows for determination of the parameters of the system for which vibration amplitudes of crane boom are the lowest. Value of $\eta$ used in computations is internal damping coefficient of homogeneous structural steel without coating (Liang et al., 1998). Selected values of $\mu$ from 0 to 2 describe the main effect of constructional damping coefficient on damped vibration frequency and on the degree of vibration amplitude decay. No effect on $\operatorname{Re}\left(\omega^{*}\right)$ and $\operatorname{Im}\left(\omega^{*}\right)$ for $\mu=0$ was found whereas the highest effect on $\operatorname{Im}\left(\omega^{*}\right)$ and $\operatorname{Re}\left(\omega^{*}\right)$ was observed for $\mu=0.6$ and $\mu>2$, respectively. Limitation of the scope of the study to the analysis of the first eigenvalue of the system results from its fundamental importance to engineering practice.

\section{Acknowledgement}

This research was supported by the Ministry of Science and Higher Education in 2018, Warsaw, Poland.

\section{References}

Cekus, D. and Posiadała, B. (2011): Vibration Model and Analysis of Three-Member Telescopic Boom with Hydraulic Cylinder for Its Radius Change. International Journal of Bifurcation and Chaos in Applied Sciences and Engineering, 21, 10, pp. 2883-2892.

Chin, C. and Nayfeh, A.H. and Abdel-Rahman, E. (2001) Nonlinear dynamics of a boom crane. Journal Vibration Control, 7, pp. 199-220.

Geisler, T. and Sochacki, W. (2011): Modelling and research into the vibrations of truck crane. Scientific Research of the Institute of Mathematics and Computer Science, 10, 1, pp. 49-60.

Liang, J. W. and Feeny, B. F. (1998) Identifying Coulomb and viscous friction from free vibration decrements. Nonlinear Dynamics, 16, pp. 337-347.

Sochacki, W. and Tomski, L. (1999): Free and parametric vibration of the system: telescopic boom-hydraulic cylinder (changing the crane radius). The Archive of Mechanical Engineering, 46, pp. 257-271.

Sochacki, W. (2007): The dynamic stability of a laboratory model of a truck crane. Thin-Walled Structures, 45, pp. 927-930.

Sochacki, W. and Bold, M. (2014) Modelling and Analysis of Damping in Slides of Truck-Mounted Crane Boom. Machine Dynamics Research, 38, 2, pp. 133-139.

Sochacki, W. and Bold, M. (2015a) Effect of Structural Damping on Vibration of a Truck-Mounted Telescopic Crane, in: AIP Conf. Proc. Vol.1648 Int. Conf. on Numerical Analysis and Applied Mathematics (ICNAAM), Rhodes, Greece, pp. 850058-1- 850058-4.

Sochacki, W. and Bold, M. (2015b) Damped Vibration of the System of Changing the Crane Boom Radius. Journal of Applied Mathematics and Computational Mechanics, 14, 2, pp. 111-122. 